\title{
Potential impact on prevalence of obesity in the UK of a $20 \%$ price increase in high sugar snacks: modelling study
}

\author{
Pauline F D Scheelbeek, ${ }^{1,2}$ Laura Cornelsen, ${ }^{3}$ Theresa M Marteau, ${ }^{4}$ Susan A Jebb, ${ }^{5}$ \\ Richard D Smith ${ }^{6}$
}

For numbered affiliations see end of the article.

Correspondence to:

P F D Scheelbeek

pauline.scheelbeek@lshtm.ac.uk (or @lshtm_planet on Twitter; ORCID 0000-0002-6209-2284)

Additional material is published online only. To view please visit the journal online.

Cite this as: $B M J$ 2019;366:14786 http://dx.doi.org/10.1136/bmj..14786

Accepted: 17 July 2019
OBJECTIVE

To estimate the potential impact on body mass index (BMI) and prevalence of obesity of a $20 \%$ price

DESIGN

Modelling study.

SETTING

General adult population of the United Kingdom. PARTICIPANTS

36324 households with data on product level household expenditure from UK Kantar FMCG (fast moving consumer goods) panel for January 2012 to December 2013. Data were used to estimate changes in energy ( $\mathrm{kcal}, 1 \mathrm{kcal}=4.18 \mathrm{~kJ}=0.00418 \mathrm{MJ}$ ) purchase associated with a $20 \%$ price increase in high sugar snacks. Data for 2544 adults from waves 5 to 8 of the National Diet and Nutrition Survey (2012-16) were used to estimate resulting changes in BMI and prevalence of obesity.

\section{MAIN OUTCOME MEASURES}

The effect on per person take home energy purchases of a $20 \%$ price increase for three categories of high sugar snacks: confectionery (including chocolate),

\section{ABSTRACT} increase in high sugar snacks.

\section{WHAT IS ALREADY KNOWN ON THIS TOPIC}

Taxation strategies to lower sugar and energy intake have focused on sugar sweetened beverages; in the UK, high sugar snacks, such as confectionery, make a more substantial contribution to intakes of free sugars and energy than do sugar sweetened beverages

Encouraged by the large reformulation efforts of the food industry after the Soft Drink Industry Levy was introduced, Public Health England developed a voluntary sugar reduction and reformulation programme for snacks, showing modest results after the first year and highlighting the need for additional interventions to reduce sugar intake through high sugar snacks

Several countries, including Mexico, Finland, and Hungary introduced taxes on unhealthy foods, including high sugar snacks: early evaluations show a major reduction in the purchase of such foods

\section{WHAT THIS STUDY ADDS}

Our study suggests that a $20 \%$ price increase in high sugar snacks has the potential to reduce overall energy purchased among all body mass index and income groups in the UK, leading to an estimated population level reduction in obesity prevalence of 2.7 percentage points after the first year

The results of this study also suggest that price increases in high sugar snacks could also make an important contribution to reducing health inequalities driven by diet related disease

Our analysis provides policymakers with estimates of the relative magnitude of plausible impacts of a scenario of price increase in high sugar snacks and suggests that this option is worthy of further research and consideration as part of an integrated approach to tackling obesity biscuits, and cakes. Health outcomes resulting from the price increase were measured as changes in weight, BMI (not overweight (BMI $<25)$, overweight $(B M I \geq 25$ and $<30)$, and obese $(B M I \geq 30)$ ), and prevalence of obesity. Results were stratified by household income and BMI.

\section{RESULTS}

For income groups combined, the average reduction in energy consumption for a $20 \%$ price increase in high sugar snacks was estimated to be $8.9 \times 10^{3} \mathrm{kcal}(95 \%$ confidence interval $-13.1 \times 10^{3}$ to $-4.2 \times 10^{3} \mathrm{kcal}$ ). Using a static weight loss model, BMI was estimated to decrease by 0.53 (95\% confidence interval -1.01 to -0.06) on average across all categories and income groups. This change could reduce the UK prevalence of obesity by 2.7 percentage points ( $95 \%$ confidence interval -3.7 to -1.7 percentage points) after one year. The impact of a $20 \%$ price increase in high sugar snacks on energy purchase was largest in low income households classified as obese and smallest in high income households classified as not overweight.

\section{CONCLUSIONS}

Increasing the price of high sugar snacks by $20 \%$ could reduce energy intake, $\mathrm{BMI}$, and prevalence of obesity. This finding was in a UK context and was double that modelled for a similar price increase in sugar sweetened beverages.

\section{Introduction}

Over the past decades the prevalence of obesity has increased steeply, with rates tripling globally between 1975 and 2016. In 2016, about two billion adults (aged 18 or more) worldwide were overweight, of whom more than 650 million were classified as obese. ${ }^{1}$ Obesity is a major risk factor for several chronic conditions, including ischaemic heart disease, stroke, many cancers, and type 2 diabetes. ${ }^{2}$ In the UK, the prevalence of obesity among adults was estimated at $27.8 \%$ (95\% confidence interval $24.9 \%$ to $30.7 \%$ ) in $2016,{ }^{3}$ higher than the average of $19.5 \%$ reported by the Organisation for Economic Co-operation and Development. ${ }^{4}$ However, noticeable differences exist in the prevalence of obesity in relation to deprivation and income. $^{5-7}$ In 2016, 38\% of women living in the most deprived areas in England were classified as obese compared with $20 \%$ living in the least deprived areas. ${ }^{8}$ Among children aged 2-15 years, 26\% of those living in households in the lowest income fifth were classified as obese or overweight compared with $18 \%$ of children in households in the highest fifth. ${ }^{9}$

High levels of dietary free sugars increase the risk of obesity and diabetes. ${ }^{10} 11$ Sugar sweetened beverages often make up a substantial part of consumed free 
sugars, ${ }^{12}$ and they have been a major focus of policy. ${ }^{13}$ In the UK, however, high sugar snacks, such as confectionery, cakes, and biscuits make a greater contribution to intakes of free sugars as well as energy than sugar sweetened beverages. ${ }^{14}$ The National Diet and Nutrition Survey (NDNS) shows that on average sugar sweetened beverages contribute $2 \%$ of total energy and $11 \%$ of free sugar intake compared with $12 \%$ of total energy and $26 \%$ of free sugar intake from biscuits, cakes, and confectionery combined. ${ }^{13}$ Reducing purchases of high sugar snacks therefore has the potential to make a greater impact on population health than that achieved by reducing the purchase of sugar sweetened beverages.

Health related taxes have been recommended by the World Health Organization and a recent task force on fiscal policies for health to reduce purchases of sugar sweetened beverages. ${ }^{1516}$ Early adopters of such a taxation strategy include Mexico (2014), Hungary (2012), and Finland (2011). ${ }^{17} 18$ These countries introduced taxes not only on sugar sweetened beverages but also on other unhealthy foods, including high sugar snacks. In Mexico, for example, all "nonessential foods" with 275 or more $\mathrm{kcal} / 100 \mathrm{~g}$ are taxed at $8 \%$, including biscuits and cereal bars. ${ }^{19}$ In Hungary, prepacked high sugar sweets with more than $25 \mathrm{~g}$ of sugar are taxed at 130 HUF (£0.40; €0.40; $\$ 0.40$ ) per kilogram. Finland had a tax on sweets and ice cream (about 75p per kilogram) between 2011 and 2017. Existing evaluations suggest that the tax in Hungary, which also applied to products high in salt, reduced purchases of the taxed foods by $3.4 \% .^{20}$ In Mexico the tax on non-essential foods was estimated to have reduced purchases by $5-6 \%$, with greater effects (reduction by $12.3 \%$ ) among those with higher baseline purchases of taxed foods. ${ }^{21} 22$

In the UK, the Soft Drinks Industry Levy (SDIL) came into effect in April 2018, with an 18p and 24p tax per litre on drinks containing 5 or more and 8 or more grams of sugar per 100 millilitres, respectively. ${ }^{23}$ The two tiered nature of the levy has encouraged a wave of reformulation by the beverage industry, with at least $50 \%$ of manufacturers reducing the sugar content of their products. ${ }^{23}$ Since 2016, a voluntary sugar reduction and reformulation programme has also covered 10 categories of high sugar foods that contribute most to the sugar intakes of children, which challenged producers to reduce the amount of sugar by $20 \%$ by $2020 .{ }^{13}$ After the first year, an overall $2 \%$ reduction took place compared with the interim target of $5 \%$, with particularly small reductions in confectionery. For example, between 2015 and 2017 there was only a $1 \%$ reduction in sugar content of confectionery compared with a $5-6 \%$ decline in the sugar content of yoghurt and breakfast cereals. ${ }^{24}$

Given the modest impacts of the voluntary sugar reduction programme relative to the reductions seen through reformulation of sugar sweetened beverages, where a levy is also applied, we estimated the potential impact of a price increase in high sugar snacks on total energy purchase and subsequent health. We examined these likely effects by both body mass index (BMI) and household income group to assess the potential of price increases in high sugar snacks to reduce their purchase among those with the highest BMI and therefore at greatest risk of related diseases, and to assess their potential to reduce the health inequalities arising from higher rates of obesity among those in lower income groups.

\section{Methods}

We modelled the effect of a $20 \%$ price increase in high sugar snacks on the energy purchased and used this to estimate changes in weight and prevalence of overweight (BMI $\geq 25$ and $<30$ ) and obesity (BMI >30) in the UK. We used a $20 \%$ price change, based on tax scenarios for sugar sweetened beverages in the modelling literature, ${ }^{25}$ ${ }^{26}$ and presumed that this would lead to an equivalent change in prices of high sugar snacks (fig 1).

Data on household expenditure at product level were taken from the UK Kantar FMCG (fast moving consumer goods) panel ( $\mathrm{n}=36324$ households) for January 2012 to December 2013. ${ }^{27}$ The household sample is representative of the population in Great Britain for household size, number of children, social class, geographical region, and age of the main shopper. These data have been used in numerous studies in the UK to understand patterns of food demand (eg, ${ }^{28}$ ) and have been shown to compare well to the Living Cost and Food Survey, which is the official government data collection on household expenditures. ${ }^{30} 31$ Participants are recruited by Kantar to the open panel through post and e-mail, and Kantar assess panel representativeness at intervals of four weeks. Households supply data on items purchased and brought home by scanning barcodes of the products and sending in digital images of cash register receipts. Households are additionally supplied with barcodes to record purchases of unpackaged products, such as fruit and vegetables. The dataset includes information on purchases (volume and expenditure) of food and drinks from a wide range of outlets, including large retailers, supermarkets, butchers, greengrocers, and corner shops. The data exclude all purchases of food and beverages not brought home (eg, consumed away from home). Explicit comparison and validation studies of Kantar FMCG data in comparison to the Living Cost and Food Survey are available for earlier years (2003-09) and show a good fit. Furthermore, the use of data on commercial food purchases for public health research is growing and has been deemed a valuable tool for nutrition research. ${ }^{32}$

As in a previous study ${ }^{33}$ we aggregated data from all foods and beverages into 13 distinct groups. As high sugar snacks were the focus of this study, we included three categories, defined as high sugar products at ambient temperature-typically to be consumed on the go without utensils. These were confectionery (including chocolate), biscuits, and cake (piece, slice, or portion). The last group did not include larger cakes (meant for sharing) and proved to be the least straightforward category to assign. 


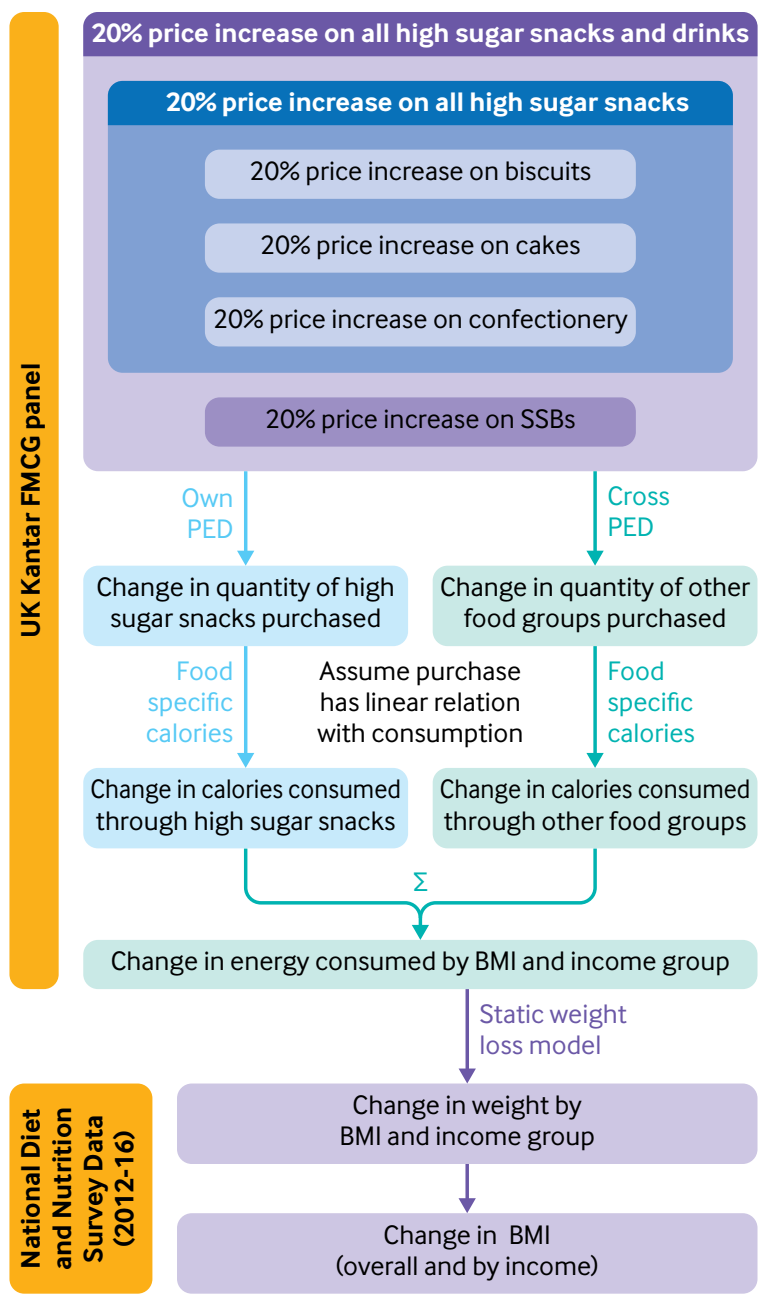

Fig 1 | Modelled causal pathway between price increases in high sugar snacks and changes in weight and obesity. $\mathrm{PED}=$ price elasticity of demand; $\mathrm{BMI}=$ body mass index; FMCG=fast moving consumer goods; SSBs=sugar sweetened beverages

The impact of price changes on the demand for a product is the price elasticity of demand (PED). This indicates the change in demand-expressed as a percentage-given a $1 \%$ change in price. It is divided into "own PED," showing the change in demand for a certain product if its own price changed, and "cross PED" showing the change in demand for a certain product if the price of other products changed. For this study, we calculated own PED and cross PED by income and BMI of the main household purchaser using an adapted version of the Almost Ideal Demand System, which is described in detail elsewhere. ${ }^{33}$ The total sample size was 36324 for estimating own PED and cross PED by income and 27115 by household income and BMI group (this is different from the sample sizes in the energy purchase analysis). Group specific own PED are reported in appendix table $\mathrm{B}$, and cross PEDs can be found in the technical appendix.

Data on the energy content of the foods and beverages purchased are recorded twice a year by Kantar from products available in the market. Average baseline daily purchases of energy were estimated using 2013 data only ( $\mathrm{n}=32620$ households) and calculated as per household member per day, without adjustment for age or sex. Baseline purchases were expressed in weighted means to account for sampling selection of the panel and underreporting using pooled weights provided with the data.

\section{Statistical analyses}

Analyses were carried out on the full sample and subsamples by annual income (low $<£ 20000$, middle $£ 20000-49999$, and high $\geq € 50000$ ) and BMI (not overweight (BMI <25), overweight $(25$ to $<30)$, and obese $(\geq 30)$ ) of the main household purchaser-that is, the person generally responsible for food purchase in a household. As not all participants on the 2013 database reported income (11\% missing, 3554 households), the final estimation sample used to estimate changes included 29066 households. BMI data were missing from a further 13\% (4290 households), hence the number of participants for the stratified analysis by BMI group equalled 24776.

We used the own PED and cross PED matrix for all BMI and income groups to estimate change in per person energy purchase simulating a $20 \%$ price increase in one or multiple high sugar snack groups. New energy purchase totals per income or BMI group, or both were constructed by totalling scenario specific energy purchases for each food group. Confidence intervals of changes in energy purchase were constructed using intragroup variability of energy purchase as well as variance of estimates for own PEDs and cross PEDs (see equations 1 and 2 in the technical appendix).

To estimate the combined effect of multiple price increases on energy purchase we used a chained version of the methods previously described. This covered the combined effect of a $20 \%$ price increase in confectionery, biscuits, and cake.

We used the change in average energy purchased per household member (unadjusted for age or sex) as a proxy for change in energy intake of the main purchaser to estimate change in weight. A static model estimated average weight change for each BMI and income group (see equation 3 in the technical appendix) based on change in energy intake. An average of $7715 \mathrm{kcal} / \mathrm{kg}$ ( $1 \mathrm{kcal}=4.18 \mathrm{~kJ}=0.00418 \mathrm{MJ})$ weight loss was used, with a standard deviation of 245 kcal (representing a 7\% coefficient of variation and assumed a normal distribution, in line with values reported in the literature for energy expenditure in healthy adults $\left(\mathrm{eg},{ }^{3435}\right)$. We disregarded any changes in energy expenditure resulting from weight fluctuations, as we expected the change in weight and hence energy expenditure to be small over the course of one year. For each subgroup we ran 1000 Monte Carlo simulations using best estimates, variance of change in energy purchase and variance of energy expenditure.

The derived weight loss was used to estimate changes in BMI and prevalence of overweight and obesity in adults ( $\geq 16$ years) based on data from the National Diet and Nutrition Survey (NDNS) waves 5 to $8\left(2012-16 ; n=3145\right.$ adults $\left.^{36}\right)$. Data on household 
income were missing for 447 (14.2\%) adults and for BMI in a further 154 (4.9\%), hence analyses were performed on 2544 adults. The NDNS is a nationally representative, rolling cross sectional survey designed to "collect detailed, quantitative information on the food consumption, nutrient intake and nutritional status of the general population." ${ }^{36}$ A trained data collector measures height and weight of participants and therefore data are less prone to (non-differential) misclassification than self report. Data on consumption of high sugar snacks were also available in NDNS. As these were self reported quantities-and therefore potentially prone to non-differential underreportingin our view the data from the Kantar FMCG panel are more accurate for our baseline energy purchase data in the previous steps described. Body weight for each NDNS participant was projected by subgroup, running 1000 Monte Carlo simulations using best estimates and variance of weight loss and BMI. Details of the uncertainty approach applied can be found in the technical appendix.

Data from the Kantar FMCG panel include households with and without children, with food purchases registered at household level. The proportional share of purchased foods that is consumed by children in the household could vary greatly, with potential to impact on the results of the models. We therefore performed sensitivity analyses for several steps of the model whereby households with one or more children were excluded.

\section{Patient and public involvement}

The public was not involved in the design, execution, and interpretation of this study. All data used in this study are, however, nationally representative and obtained through public panels (Kantar) and samples of the public (NDNS).

\section{Results}

Supplementary appendix 1 provides descriptive characteristics of the sample population, body mass index (BMI), income specific own price elasticity of demands (PEDs) and cross PEDs, and baseline purchases of energy (for each household member per day).

Overall, the own PED ranged between -0.29 and -1.06 , with high income households showing generally least price sensitive demand across foods and beverages. Households classified as obese or overweight were less price responsive than those classified as normal weight, except for two food groups (confectionery and "other" drinks (eg, juice)). Baseline energy purchases ranged between 1808 and 2406 kcal (1 kcal=4.18 kJ=0.00418 MJ) per day for each household member. The baseline energy purchases were highest for low income households and lowest for high income households. In each income group, households classified as obese purchased most energy.

Table 1 shows the estimated changes per year in purchases of energy by household income group, based on a $20 \%$ price increase in each of the three categories of high sugar snacks, as well as the combined effect.
A $20 \%$ price increase in confectionery and biscuits, or both reduced energy purchased across all income groups. The analysis on confectionery showed a more prominent reduction in energy purchase among low income households compared with middle and high income households. A 20\% price increase in biscuits showed a less prominent reduction in energy purchase among high income households compared with low and middle income households. Results for cakes were mixed: among low income households, a 20\% price increase led to a small increase in energy purchases primarily driven by the substitution effect towards other foods. For income groups combined, the average change in energy consumption for a price increase in high sugar snacks was $-8.9 \times 10^{3} \mathrm{kcal}(95 \%$ confidence interval $-13.1 \times 10^{3}$ to $\left.-4.2 \times 10^{3} \mathrm{kcal}\right)$. Sensitivity analysis revealed that the modelled impact of price changes on energy purchase was marginally more profound in households without children, especially low income households. Differences were, however, not statistically significant (see supplementary appendix 2).

Figure 2 shows change in energy purchase of the further stratified analysis. using income and BMI specific own PEDs and cross PEDs. Price increases in each of the high sugar snack groups, and their combinations, were associated with a reduction overall in energy purchased among all BMI and income groups, with two exceptions that showed small increases (a price increase in cakes in households classified as low income and overweight and those classified as low income and obese). Among the three high sugar snack groups, price increases in biscuits showed the strongest reduction in energy purchased in the group classified as obese, with the greatest effects in low income households. Households classified as not being overweight appeared to be most responsive to price increases in confectionery (including chocolate), especially among low income households. The impact of price increases in various snack groups in the group classified as overweight showed no clear pattern.

Average annual change in energy purchase per person for those classified as obese, based on a $20 \%$ price increase in high sugar snacks, was $-13.1 \times 10^{3}$ kcal $\left(95 \%\right.$ confidence interval $-15.5 \times 10^{3}$ to $-10.7 \times 10^{3}$ $\mathrm{kcal}$ ) for low income households, $-11.6 \times 10^{3} \mathrm{kcal}$ $\left(-13.6 \times 10^{3}\right.$ to $\left.-9.6 \times 10^{3} \mathrm{kcal}\right)$, for middle income households, and $-11.1 \times 10^{3} \mathrm{kcal}\left(-14.8 \times 10^{3}\right.$ to $-7.4 \times 10^{3} \mathrm{kcal}$ ) for high income households (fig 2).

Among households classified as obese, the effect of price increases in biscuits and confectionery on energy purchase varied by income: those from low income households showed most responsive to price increases compared with those from middle and high income households, leading to relatively larger reductions in energy purchase in the low income households. Among households classified as overweight, similar reductions in energy purchased were observed in middle and high income households, whereas price increases in high sugar snacks in overweight low income households were associated with relatively small reductions in energy purchased. 


\begin{tabular}{|c|c|c|c|c|c|}
\hline \multirow[b]{2}{*}{ Household income (f) } & \multirow[b]{2}{*}{ No of participants } & \multicolumn{4}{|c|}{ Change in annual energy $(\mathrm{kcal})$ purchase $(95 \% \mathrm{Cl})$ with $20 \%$ price increase } \\
\hline & & Biscuits & Confectionery* & Caket & High sugar snacks \\
\hline Low $(<20000)$ & 10308 & $-3709(-4401$ to -3016$)$ & $-4805(-5326$ to -4284$)$ & 1052 (1316 to 789$)$ & $-6855(-10034$ to -3675$)$ \\
\hline Middle (20 000-49999) & 14332 & $-4395(-5011$ to -3780$)$ & $-3319(-3622$ to -3015$)$ & $-3073(-3745$ to -2401$)$ & $-10469(-14711$ to -6227$)$ \\
\hline High $(\geq 50000)$ & 4426 & $-1640(-2126$ to -1154$)$ & $-3230(-3797$ to -2662$)$ & $-4182(-5860$ to -2403$)$ & $-9001(-16039$ to -1962$)$ \\
\hline All & 29066 & $-3732(-4409$ to -3056$)$ & $-3832(-4257$ to -3407$)$ & $-1779(-2296$ to -1262$)$ & $-8964(-13772$ to -4155$)$ \\
\hline
\end{tabular}

Sensitivity analysis excluding households with children showed similar but slightly more profound effects of price increases on energy purchaseespecially among obese low income households. The differences with the main model were not, however, statistically significant (see supplementary appendix 2). Analyses were repeated including a Bonferroni correction for multiple comparisons. Uncertainty around the estimates increased by about $16 \%$ on average, but all changes in energy purchase from high sugar snacks remained significant (see supplementary appendix 3).

Figure 3 compares the impact of two (independent) price increase scenarios (20\% price increase in sugar sweetened beverages and $20 \%$ price increase in high sugar snacks) on annual energy purchase. The impact of price increases in high sugar snacks was substantially larger on energy purchased than an equivalent price increase in sugar sweetened beverages throughout all income and BMI groups. Following the scenario of a $20 \%$ price increase in sugar sweetened beverages, in households classified as obese the annual purchase of energy changed by $-2.1 \times 10^{3} \mathrm{kcal}\left(-2.6\right.$ to $-1.5 \times 10^{3}$ $\mathrm{kcal}),-0.3 \times 10^{3} \mathrm{kcal}\left(-0.4\right.$ to $\left.-0.1 \times 10^{3} \mathrm{kcal}\right)$, and $3.5 \times 10^{3} \mathrm{kcal}\left(2.2\right.$ to $\left.4.8 \times 10^{3} \mathrm{kcal}\right)$, for low, middle, and high income households, respectively. These are lower than the changes resulting from a $20 \%$ price increase in high sugar snacks.
Table 2 shows the results of modelled weight changes over one year by household income and BMI, based on changes in energy purchased, under the assumption that change in energy purchased is a proxy for change in energy consumption. A $20 \%$ price increase in high sugar snacks and sugar sweetened beverages was estimated to result in weight changes varying from $-911 \mathrm{~g}$ (95\% confidence interval -1115 to $-707 \mathrm{~g}$ ) in the overweight low income households to $-2100 \mathrm{~g}(-2530$ to $-1671 \mathrm{~g})$ in middle income overweight households one year after the introduction of the price increase.

Pooling all BMI and income groups, a price increase of high sugar snacks and beverages combined is estimated to decrease BMI on average by -0.53 (95\% confidence interval -1.01 to -0.06$)$. In households classified as obese this ranged from $-0.36(-0.63$ to -0.09 ) for high income to -0.72 ( -1.03 to -0.41$)$ for low income households a year after the introduction of the price increase (see supplementary appendix 4).

A positive weight gain was estimated for a $20 \%$ price increase in sugar sweetened beverages among high income households classified as obese. This could be explained by substitution towards high sugar snacks with higher energy content (see supplementary appendix). For households in the same income category but classified as not overweight or overweight the impact of a price increase in sugar



Fig 2 I Impact of $20 \%$ price increase in high sugar snacks on change in annual energy purchase by body mass index (BMI) and household income. Stratification by household income (low $<f 20000$, middle $f 20000-49999$, high $\geq f 50000)$ and $B M I .1 \mathrm{kcal}=4.18 \mathrm{~kJ}=0.00418 \mathrm{MJ}) . \mathrm{f1.00}=\$ 1.2 ; € 1.1$. Confectionery includes chocolate. Whiskers represent $95 \%$ confidence intervals 


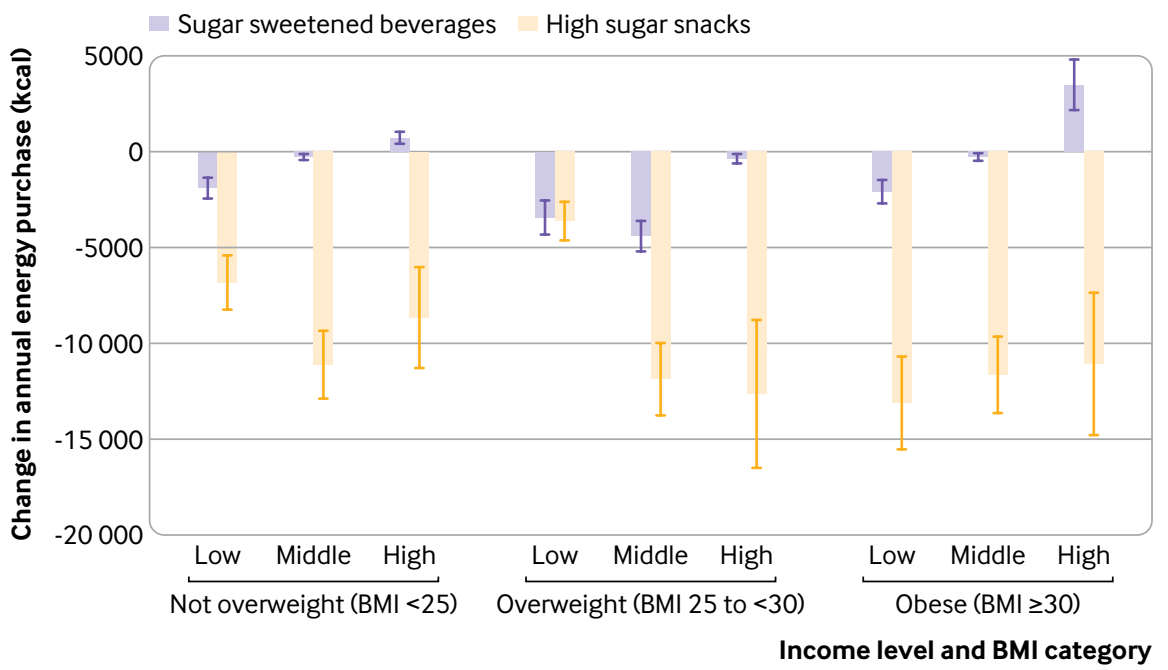

Fig 3 Impact of $20 \%$ price increase in sugar sweetened beverages and high sugar snacks on change in annual energy purchase by body mass index (BMI) and household income group. Stratification by income group (low $<\mathrm{f} 20000$, middle $f 20000-49999$, high $\geq £ 50000$ ) and $B M I$ group. $f 1.00=\$ 1.2$; $€ 1.1$. Whiskers represent $95 \%$ confidence intervals

sweetened beverages on weight change was marginal to statistically and clinically non-significant.

The projection of the estimated weight changes on a representative sample of the UK population shows a noticeable shift in the population distribution of BMI, with a decrease in the proportion classified as obese (BMI $\geq 30$ ) and an increase in the proportion classified as not overweight $(\mathrm{BMI}<25)$. The simulated decreases in the prevalence of obesity are most marked in low and middle income households. Based on a $20 \%$ price increase in high sugar snacks, the prevalence of obesity after one year would decrease by 3.1 percentage points ( $95 \%$ confidence interval -3.6 to -2.6 percentage points) in low income households, 2.5 percentage points ( -2.9 to -2.1 percentage points) in middle income households, and 2.3 percentage points ( -3.2 to -1.5 percentage points) in high income households. For the UK population this would result in a reduction of 2.68 percentage points ( -3.7 to -1.7 percentage points) in the prevalence of obesity (see supplementary appendix 5).

\section{Discussion}

A $20 \%$ price increase in high sugar snacks has the potential to reduce overall energy purchased among all body mass index (BMI) and household income groups in the United Kingdom. The estimated population level reduction in prevalence of obesity in the first year was 2.7 percentage points.

Furthermore, our results suggest that a $20 \%$ tax on high sugar snacks could also contribute to reducing health inequalities driven by diet related disease, given the potential for the greatest reduction in sugar consumption in households classified as obese (BMI $\geq 30$ ) and low income (<£20000 annually). In low income households classified as obese and middle income households classified as overweight, weight change based on a price increase in high sugar snacks and sugar sweetened beverages combined was estimated to be about $2 \mathrm{~kg}$ after 12 months. The estimated impacts were smaller in middle and high income households classified as obese, which can partly be explained by the differences in own price elasticity of demands (PEDs) and cross PEDs and also by the greater volume of high sugar snacks and beverages purchased in low income households classified as obese.

Our analysis followed an energy intake "pathway" to estimate the impact of a $20 \%$ price increase and subsequent reduced purchase of high sugar snacks and beverages (as a proxy for consumption) on body weight. In addition to this pathway, there could be other, direct adverse health impacts of high sugar intake, with reported increased risks of diabetes and several cardiovascular diseases. ${ }^{37}$ Reducing the purchase of high sugar snacks therefore might have additional benefits to population health than the ones assessed in this study.

We used a $20 \%$ price increase in a group of high sugar snacks to reflect the broad approach that has been undertaken for tax scenarios concerning sugar sweetened beverages in the modelling literature. ${ }^{25} 26$ An alternative is to consider a tax related to nutrients, ${ }^{38}$ which in this case could be sugar or total energy. Most recent government proposals of health related food policies do use a nutrient profile model, which also takes into account "positive" contributions, such as fruit and vegetable or fibre content of the product. However, this generates increased complexity in both policy and analysis, and although this should be explored in future research for our purposes, the $20 \%$ price increase seemed most appropriate.

\section{Research in context}

An observational study evaluating the (short term) impact of an $8 \%$ tax on energy dense, nutrient poor 


\begin{tabular}{|c|c|c|c|c|c|c|c|}
\hline \multirow[b]{2}{*}{$\begin{array}{l}\text { BMI group by } \\
\text { household income }\end{array}$} & \multirow[b]{2}{*}{$\begin{array}{l}\text { No of } \\
\text { participants }\end{array}$} & \multicolumn{6}{|c|}{ Change in weight $(\mathrm{g})(95 \% \mathrm{Cl})$} \\
\hline & & Beverages & Biscuits & Confectionery¥ & Cake & $\begin{array}{l}\text { High sugar } \\
\text { snacks }\end{array}$ & $\begin{array}{l}\text { Beverages and } \\
\text { snacks }\end{array}$ \\
\hline \multicolumn{8}{|l|}{ Not overweight: } \\
\hline Low & 372 & $\begin{array}{l}-247 \\
(-316 \text { to }-178)\end{array}$ & $\begin{array}{l}-152 \\
(-189 \text { to }-115)\end{array}$ & $\begin{array}{l}-645 \\
(-748 \text { to }-543)\end{array}$ & $\begin{array}{l}-180 \\
(-229 \text { to }-129)\end{array}$ & $\begin{array}{l}-889 \\
(-1340 \text { to }-439)\end{array}$ & $\begin{array}{l}-1136 \\
(-1387 \text { to }-885)\end{array}$ \\
\hline Middle & 473 & $\begin{array}{l}-35.7 \\
(-74.9 \text { to } 3.4)\end{array}$ & $\begin{array}{l}-419 \\
(-501 \text { to }-336)\end{array}$ & $\begin{array}{l}-578 \\
(-661 \text { to }-495)\end{array}$ & $\begin{array}{l}-505 \\
(-644 \text { to }-366)\end{array}$ & $\begin{array}{l}-1451 \\
(-2123 \text { to }-780)\end{array}$ & $\begin{array}{l}-1494 \\
(-1801 \text { to }-1188)\end{array}$ \\
\hline High & 191 & $\begin{array}{l}97.5 \\
\text { (3.0 to 192) }\end{array}$ & $\begin{array}{l}-115 \\
(-211 \text { to }-8.4)\end{array}$ & $\begin{array}{l}-521 \\
(-631 \text { to }-411)\end{array}$ & $\begin{array}{l}-524 \\
(-773 \text { to }-276)\end{array}$ & $\begin{array}{l}-1126 \\
(-2057 \text { to }-195)\end{array}$ & $\begin{array}{l}-1010 \\
(-1343 \text { to }-678)\end{array}$ \\
\hline \multicolumn{8}{|l|}{ Overweight: } \\
\hline Low & 273 & $\begin{array}{l}-445 \\
(-570 \text { to }-321)\end{array}$ & $\begin{array}{l}-472 \\
(-582 \text { to }-363)\end{array}$ & $\begin{array}{l}-495 \\
(-575 \text { to }-415)\end{array}$ & $\begin{array}{l}+395 \\
(287 \text { to } 504)\end{array}$ & $\begin{array}{l}-473 \\
(-717 \text { to }-229)\end{array}$ & $\begin{array}{l}-911 \\
(-1115 \text { to }-707)\end{array}$ \\
\hline Middle & 440 & $\begin{array}{l}-574 \\
(-702 \text { to }-445)\end{array}$ & $\begin{array}{l}-809 \\
(-967 \text { to }-651)\end{array}$ & $\begin{array}{l}-423 \\
(-483 \text { to }-362)\end{array}$ & $\begin{array}{l}-346 \\
(-442 \text { to }-250)\end{array}$ & $\begin{array}{l}-1544 \\
(-2259 \text { to }-830)\end{array}$ & $\begin{array}{l}--2100 \\
(-2530 \text { to }-1671)\end{array}$ \\
\hline High & 156 & $\begin{array}{l}-48.1 \\
(-70.1 \text { to } 0.8)\end{array}$ & $\begin{array}{l}-418 \\
(-543 \text { to }-293)\end{array}$ & $\begin{array}{l}-539 \\
(-653 \text { to }-424)\end{array}$ & $\begin{array}{l}-665 \\
(-981 \text { to }-349)\end{array}$ & $\begin{array}{l}-1646 \\
(-3005 \text { to }-287)\end{array}$ & $\begin{array}{l}-1726 \\
(-2291 \text { to }-1162)\end{array}$ \\
\hline \multicolumn{8}{|l|}{ Obese: } \\
\hline Low & 266 & $\begin{array}{l}-270 \\
(-346 \text { to }-194)\end{array}$ & $\begin{array}{l}-1023 \\
(-1254 \text { to }-793)\end{array}$ & $\begin{array}{l}-762 \\
(-884 \text { to }-640)\end{array}$ & $\begin{array}{l}41.4 \\
(-21.6 \text { to } 104.3)\end{array}$ & $\begin{array}{l}-1706 \\
(-2568 \text { to }-844)\end{array}$ & $\begin{array}{l}-1987 \\
(-2423 \text { to }-1550)\end{array}$ \\
\hline Middle & 292 & $\begin{array}{l}-32.3 \\
(-141.6 \text { to } 76.9)\end{array}$ & $\begin{array}{l}-879 \\
(-1051 \text { to }-706)\end{array}$ & $\begin{array}{l}-399 \\
(-457 \text { to }-340)\end{array}$ & $\begin{array}{l}-270 \\
(-345 \text { to }-194)\end{array}$ & $\begin{array}{l}-1512 \\
(-2213 \text { to }-810)\end{array}$ & $\begin{array}{l}-1604 \\
(-1935 \text { to }-1274)\end{array}$ \\
\hline High & 81 & $\begin{array}{l}457 \\
(298 \text { to } 616)\end{array}$ & $\begin{array}{l}-531 \\
(-690 \text { to }-371)\end{array}$ & $\begin{array}{l}-393 \\
(-479 \text { to }-307)\end{array}$ & $\begin{array}{l}-551 \\
(-815 \text { to }-288)\end{array}$ & $\begin{array}{l}-1448 \\
(-2648 \text { to }-247)\end{array}$ & $\begin{array}{l}-1024 \\
(-1365 \text { to }-684)\end{array}$ \\
\hline All & 2544 & $\begin{array}{l}-203 \\
(-269 \text { to }-137)\end{array}$ & $\begin{array}{l}-550 \\
(-691 \text { to }-409)\end{array}$ & $\begin{array}{l}-538 \\
(-633 \text { to }-444)\end{array}$ & $\begin{array}{l}-262 \\
(-361 \text { to }-162)\end{array}$ & $\begin{array}{l}-1301 \\
(-2088 \text { to }-513)\end{array}$ & $\begin{array}{l}-1511 \\
(-1898 \text { to }-1121)\end{array}$ \\
\hline
\end{tabular}

foods (including high sugar snacks) introduced in Mexico in 2014, concluded that the tax statistically significantly reduced the purchase of these foods in urban areas: reductions up to $15 \%$ were reported for southern Mexico. ${ }^{39}$ The tax intervention covered a much larger variety of foods than in our study, whereas the tax rate was lower, making it difficult to compare results. The authors concluded, however, that the strategy generated substantial revenue that could be used to finance policies for the treatment and prevention of obesity ${ }^{39}$ : a $20 \%$ price increase in high sugar snacks could generate similar opportunities for obesity control in the UK.

Evidence from studies directly evaluating the economic and health impact of sugar taxation strategies was sparse. Although the taxation on sugar sweetened beverages was first introduced in the early 2010s, the lagged impact of dietary interventions limits the possibilities of accurately assessing the health impacts and contribution to the reduction of health inequalities in observational study designs. Although modelling studies project these to be favourable for lower socioeconomic groups, ${ }^{40-42}$ the results of observational studies remain inconclusive; specifically for sugar taxation. ${ }^{43} 44$ It could be hypothesised that taxation strategies targeting non-essential foods that are high in sugar but have otherwise low additional nutritional value would have low regressive financial effects, similar to those of other non-essential products, such as sugar sweetened beverages, or even alcohol and tobacco. ${ }^{44}$

Our findings on daily calorie reductions from sugar sweetened beverages concur with previous results for a similar price increase, ${ }^{45}$ but they are much lower than that study's estimates based on larger price increases of $18-75 \%{ }^{26}$

The estimated reduction of 0.53 in BMI with a $20 \%$ price increase is relatively large compared with other population level interventions aimed at weight reduction. For example, a recent study on active travel to work in the UK found that the BMI of people transitioning from car to active commuting decreased by 0.30 ( $95 \%$ confidence interval -0.47 to -0.13 ) after 4.4 years of follow-up. ${ }^{46}$ A systematic review and meta-analysis found a similar reduction, of 0.71 (-1.19 to-0.23), when the impact of walking group interventions was evaluated. ${ }^{47}$

Price increases in cakes were associated with increased energy purchased in two low incomes groups-those of households classified as overweight and those of households classified as obese. This could likely be explained by substitution towards more energy dense alternatives for cakes: a daily reduction of about 3-6 kcal from cakes was matched with an increase of about 16-18 kcal from substitutes (see the technical appendix). A similar increase in energy purchased was found for households classified as high income and obese. This could be related to positive cross PED towards the "other" group (aggregate of all remaining foods not allocated to a specific food group): a group providing nearly half of the daily energy intake.

In this UK based study we found a relatively high impact on overall energy purchased, and subsequent weight changes, of a $20 \%$ price increase in high sugar snacks versus sugar sweetened beverages. These results might also apply to other high income countries with similar consumption patterns of these two food groups, such as Australia, but might not 
align with countries with a much higher consumption of sugar sweetened beverages or a higher drinks to snacks ratio-such as the US or Mexico, where the effect of price increases in high sugar snacks might be less noticeable ${ }^{48}$ (see supplementary appendix 6). Regardless of the beverage versus snack purchase ratio, joint policies are expected to be approximately additive.

\section{Strengths and limitations of this study}

The current study has several strengths. We modelled the effect of a price increase across a range of high sugar snacks. We also obtained information from several high quality databases comprising primary data on food purchase, food intake, and BMI of a representative national sample of the UK population. Data from the Kantar FMCG (fast moving consumer goods) panel, on which we based our predicted elasticity estimates and baseline purchases across the food groups, has been shown to produce similar estimates of budget and budget shares, compared with the Living Cost and Food Survey, the official, UK government collected data for household expenditures. ${ }^{30} 31$

This study has a few limitations. Firstly, we excluded $25 \%$ of the households from analysis because of missing information on either income or BMI. It is unlikely that such missing information is related to price elasticity or purchase behaviour. As we present stratum specific data, missing information was expected to have little to no influence on the group specific estimates: however, it may have resulted in some bias for the pooled values across groups. Secondly, the baseline daily energy purchase estimates are sample average estimates that do not consider age or sex of the household members who could have different energy requirements. We were unable to adjust for these factors as we did not have information on these characteristics for household members. Thirdly, we used a static model for weight loss based on changes in energy consumption, which might not fully reflect actual mechanisms of weight change. However, the period considered in this study is one year, and modelled weight changes during that time were expected to be relatively small. Therefore changes in energy expenditure, as described previously, are expected to have marginal impacts on our results. ${ }^{49}$ Nonetheless, the model outcomes should be regarded as estimates on the order of scale of any such price increase strategy and would, as with any modelling study, require further "real life experience" testing to further quantify the effects on health. Fourthly, the study does not reflect on the substitution of nutrients alongside changes in energy. For example, reduction in energy from high sugar snacks could lead to substitution of other foods that are lower in energy content but perhaps higher in other nutrients of concern, such as saturated fats or salt. The health impacts of such substitutes should be further analysed and considered in the decision making process around food price policies. Furthermore, the satiety index of sugary snacks can vary greatly: some high sugar snacks could reduce overeating at meals, hence the overall impact of reduced consumption of high sugar snacks would be partly cancelled out by consumption of larger portions during mealtimes. Studies of sugary drinks only would be prone to this phenomenon, as the satiety effect of sugar sweetened beverages is generally low. ${ }^{50}$ Fifthly, we assumed that all food purchased was consumed, which is unlikely, and some food will inevitably be waste. However, although the link between purchasing and consumption is far from perfect, it is strong $\left(\mathrm{eg},{ }^{51}\right)$, and our estimates on the effect of price rises on change in energy purchased is likely to be similar to that on consumption even if absolute values differ. The food items evaluated in this study represent take home purchases from retail outlets, such as supermarkets. Owing to lack of comparable data we did not include additional high sugar snacks purchased, for example, from cafés and restaurants and consumed on the go, and the consumption of these snacks as well as the effect of price increases might vary considerably across income groups. Our estimates of the overall effect are therefore conservative-albeit the implications on inequality are more difficult to assess a priori. Finally, we did not consider a specific pass through rate for tax (ie, the proportion of the price increase to be paid by the consumer) as found in studies evaluating food tax $\left(\mathrm{eg}^{52}\right)$ and based on evidence around linear effects of price change on consumption-specifically for sugary beverages. ${ }^{53}$ As we specifically studied the effect of a $20 \%$ price increase to the consumer, it is less relevant whether this would be a true reflection of a particular pass through rate in the UK.

\section{Conclusions}

Increasing the price of high sugar snacks by $20 \%$ could reduce energy intake and BMI to more than twice that observed for similar price increases on sugar sweetened beverages, but with strong variability across household income and BMI groups. Furthermore, evaluations of price increases on sugar sweetened beverages-- which faced similar analytical limitations to our study-have shown reductions in purchases closely aligned to the modelled predictions, suggesting price elasticities were reasonably valid. Although this might differ for high sugar snacks, it cannot be tested until such policies are implemented. Meanwhile this analysis provides policymakers with estimates of the relative magnitude of plausible impacts if a scenario of price increase in high sugar snack were to be implemented and suggests that this option is worthy of further research and consideration as part of an integrated approach to tackling obesity.

\section{AUTHOR AFFILIATIONS}

${ }^{1}$ Department of Population Health, London School of Hygiene and Tropical Medicine, London WC1E 7HT, UK

${ }^{2}$ Centre on Climate Change and Planetary Health, London School of Hygiene and Tropical Medicine, London, UK

${ }^{3}$ Department of Public Health, Environments and Society, London School of Hygiene and Tropical Medicine, London, UK

${ }^{4}$ Behaviour and Health Research Unit, Institute of Public Health, University of Cambridge, Cambridge, UK 
${ }^{5}$ Nuffield Department of Primary Care Health Sciences, University of Oxford, Oxford, UK

${ }^{6}$ College of Medicine and Health, University of Exeter, Exeter, UK

Contributors: PFDS did the literature search, analysed and interpreted the data, and wrote the manuscript. LC did the literature search, designed the study, analysed and interpreted the data, and commented on the manuscript. PFDS and LC are guarantors. TMM designed the study, interpreted the data, and commented on the manuscript. SAJ designed the study, interpreted the data, and commented on the manuscript. RS designed the study, analysed and interpreted the data, and commented on the manuscript. The final version of the report and ultimate decision to submit for publication was determined by the authors. The corresponding author attests that all listed authors meet authorship criteria and that no others meeting the criteria have been omitted.

Funding: This study was independent research funded by the National Institute for Health Research (NIHR) Policy Research Programme (Policy Research Unit in Behaviour and Health (PR-UN-0409-10109 principal investigator TMM)). PS is funded by the Wellcome Trust (205200/Z/16/Z). LC is funded by an MRC fellowship grant (MR/ P021999/1). SAJ is funded by the Oxford NIHR Biomedical Research Centre and Oxford NIHR Collaboration and Leadership in Applied Health Research and Care. The views expressed in this publication are those of the authors and not necessarily those of the NHS, the National Institute for Health Research, the Department of Health and Social Care or its non-departmental agencies and public bodies and other government departments. The final version of the report and ultimate decision to submit for publication was determined by the authors.

Competing interests: All authors have completed the ICMJE uniform disclosure form at www.icmje.org/coi disclosure.pdf and declare: support from the National Institute for Health Research Policy Research Programme (Policy Research Unit in Behaviour and Health (PR-UN-0409-10109 principal investigator TMM)); no financial relationships with any organisations that might have an interest in the submitted work in the previous three years; no other relationships or activities that could appear to have influenced the submitted work.

Ethical approval: Not required as the data used in this study are secondary, anonymised purchase and open access data. No patients were involved in the study.

Data sharing: No additional data available.

The lead author (PFDS) affirms that this manuscript is an honest, accurate, and transparent account of the study being reported; that no important aspects of the study have been omitted; and that any discrepancies from the study as planned (and, if relevant, registered) have been explained.

This is an Open Access article distributed in accordance with the terms of the Creative Commons Attribution (CC BY 4.0) license, which permits others to distribute, remix, adapt and build upon this work, for commercial use, provided the original work is properly cited. See: http://creativecommons.org/licenses/by/4.0/.

1 World Health Organization. Obesity and Overweight 2018: www.who. int/news-room/fact-sheets/detail/obesity-and-overweight [Accessed 13 July 2019].

2 Guh DP, Zhang W, Bansback N, Amarsi Z, Birmingham CL, Anis AH. The incidence of co-morbidities related to obesity and overweight: a systematic review and meta-analysis. BMC Public Health 2009;9:88 doi:10.1186/1471-2458-9-88

3 World Health Organization. Global Health Observatory Data Repository. 2019: http://apps.who.int/gho/data/node.main. A900A?lang=en [Accessed 13 July 2019].

4 Organisation for Economic Co-operation and Development. Obesity Update. OECD Publishing, 2017.

5 Baker C. Obesity Statistics - Briefing Paper \#3336. 2018 House of Commons Library. London.

6 Conolly A, Saunders C. Health Survey for England 2016 Adult overweight and obesity. NatCen Social Research. NHS Digital. Health and Social Care Information Centre London, 2017.

7 NatCen Social Research UCL. Health Survey for England 2016 Children's health. 2017. NHS Digital. Health and Social Care Information Centre, London.

8 National Health Services Digital. Health Survey for England 2016. Health and Social Care Information Centre, 2017.

9 Public Health England. NCMP and Child Obesity Profile. 2018

10 Malik VS, Pan A, Willett WC, Hu FB. Sugar-sweetened beverages and weight gain in children and adults: a systematic review and meta-analysis. Am J Clin Nutr 2013;98:1084-102. doi:10.3945/ ajcn.113.058362
11 Malik VS, Willett WC, Hu FB. Global obesity: trends, risk factors and policy implications. Nat Rev Endocrinol 2013;9:13-27. doi:10.1038/ nrendo.2012.199

12 Luger M, Lafontan M, Bes-Rastrollo M, Winzer E, Yumuk V, FarpourLambert N. Sugar-sweetened beverages and weight gain in children and adults: A systematic review from 2013 to 2015 and a comparison with previous studies. Obes Facts 2017;10:674-93. doi:10.1159/000484566

13 Public Health England. Sugar Reduction: Achieving the 20\%ロa technical report outlining progress to date, guidelines for industry, 2015 baseline levels in key foods and next steps. PHE Publications, 2017.

14 Public Health England. Food Standards Agency - National Diet and Nutrition Survey Results from Years 7 and 8 (combined) of the Rolling Programme (2014/2015 to 2015/2016). PHE Publications, 2018.

15 World Health Organization. Report of the commission on ending childhood obesity. WHO Publications, 2016.

16 The Task Force on Fiscal Policy for Health. Health Taxes to Save Lives: Employing Effective Exercise Taxes on Tabacco, Alcohol, and Sugary Beverages. Bloomberg Philanthropies, 2019.

17 Wright A, Smith KE, Hellowell M. Policy lessons from health taxes: a systematic review of empirical studies. BMC Public Health 2017;17:583. doi:10.1186/s12889-017-4497-z

18 Pan American Health Organization. Taxes on Sugar-sweetened Beverages as a Public Health Strategy: The Experience of Mexico. 2015. Mexico D.F.

19 Batis C, Rivera JA, Popkin BM, Taillie LS. First-year evaluation of Mexico's tax on nonessential energy-dense foods: an observational study. PLoS Med 2016;13:e1002057. doi:10.1371/journal. pmed.1002057

20 Bíró A. Did the junk food tax make the Hungarians eat healthier?Food Policy 2015;54:107-15. doi:10.1016/j.foodpol.2015.05.003

21 Taillie LS, Rivera JA, Popkin BM, Batis C. Do high vs. low purchasers respond differently to a nonessential energy-dense food tax? Two-year evaluation of Mexico's 8\% nonessential food tax. Prev Med 2017;105S:S37-42. doi:10.1016/i.ypmed.2017.07.009

22 Colchero MA, Popkin BM, Rivera JA, Ng SW. Beverage purchases from stores in Mexico under the excise tax on sugar sweetened beverages: observational study. BMJ 2016;352:h6704. doi:10.1136/bmj. h6704

23 Treasury HM. The soft drinks industry levy. Policy Paper. www.gov. uk/government/publications/soft-drinks-industry-levy/soft-drinksindustry-levy [Accessed 13 July 2019].

24 Public Health England. Sugar reduction and wider reformulation programme: Report on progress towards the first $5 \%$ reduction and next steps. 2018. London.

25 Falbe J, Rojas N, Grummon AH, Madsen KA. Higher retail prices of sugar-sweetened beverages 3 months after implementation of an excise tax in Berkeley, California. Am J Public Health 2015;105:2194201. doi:10.2105/AJPH.2015.302881

26 Briggs ADM, Mytton OT, Kehlbacher A, et al. Health impact assessment of the UK soft drinks industry levy: a comparative risk assessment modelling study. Lancet Public Health 2016;2:e15-22. doi:10.1016/S2468-2667(16)30037-8

27 UK Kantar FMCG panel. 2019. www.kantarworldpanel.com/global/ Consumer-Panels/FMCG. [Accessed 13 July 2019].

28 Quirmbach D, Cornelsen L, Jebb SA, Marteau T, Smith R. Effect of increasing the price of sugar-sweetened beverages on alcoholic beverage purchases: an economic analysis of sales data. I Epidemiol Community Health 2018;72:324-30.

29 Whybrow S, Craig L, Macdiarmid JI. Dietary patterns of households in Scotland: Differences by level of deprivation and associations with dietary goals. Nutr Health 2018;24:29-35.

30 Griffith R, O'Connell M, Smith K. Measuring the quality of people's diets: a comparison of intake and purchase data. Institute for Fiscal Studies, 2012

31 Leicester A. How might in-home scanner technology be used in budget surveys? IFS Working Paper W12/01; 2012. Institute for Fiscal Studies. London.

32 Bandy L, Adhikari V, Jebb S, Rayner M. The use of commercial food purchase data for public health nutrition research: A systematic review. PLoS One 2019;14:e0210192. doi:10.1371/journal. pone.0210192

33 Smith RD, Cornelsen L, Quirmbach D, Jebb SA, Marteau TM. Are sweet snacks more sensitive to price increases than sugarsweetened beverages: analysis of British food purchase data. BMJ Open 2018:8:e019788 doi:10.1136/bmjopen-2017-019788

34 Adriaens MP, Schoffelen PF, Westerterp KR. Intra-individual variation of basal metabolic rate and the influence of daily habitual physical activity before testing. Br / Nutr 2003:90:419-23. doi:10.1079/ BIN2003895

35 Donahoo WT, Levine JA, Melanson EL. Variability in energy expenditure and its components. Curr Opin Clin Nutr Metab Care 2004;7:599-605. doi:10.1097/00075197-200411000-00003 
36 National Diets and Nutrition Survey (NDNS). The National Diet and Nutrition Survey assesses the diet, nutrient intake and nutritional status of the general population of the UK. 2019. www.gov.uk/ government/collections/national-diet-and-nutrition-survey [Accessed 13 July 2019].

37 Yang Q, Zhang Z, Gregg EW, Flanders WD, Merritt R, Hu FB. Added sugar intake and cardiovascular diseases mortality among US adults. JAMA Intern Med 2014;174:516-24. doi:10.1001/ jamainternmed.2013.13563

38 Harding M, Lovenheim M. The effect of prices on nutrition: Comparing the impact of product- and nutrient-specific taxes. J Health Econ 2017;53:53-71. doi:10.1016/j.jhealeco.2017.02.003

39 Hernández-F M, Batis C, Rivera JA, Colchero MA. Reduction in purchases of energy-dense nutrient-poor foods in Mexico associated with the introduction of a tax in 2014. Prev Med 2019;118:16-22. doi:10.1016/i.ypmed.2018.09.019

40 Bourke EJ, Veerman JL. The potential impact of taxing sugar drinks on health inequality in Indonesia. BMJ Glob Health 2018;3:e000923. doi:10.1136/bmigh-2018-000923

41 Lal A, Mantilla-Herrera AM, Veerman L, et al. Modelled health benefits of a sugar-sweetened beverage tax across different socioeconomic groups in Australia: A cost-effectiveness and equity analysis. PLoS Med 2017:14:e1002326. doi:10.1371/journal.pmed.1002326

42 Backholer K, Sarink D, Beauchamp A, et al. The impact of a tax on sugar-sweetened beverages according to socio-economic position: a systematic review of the evidence. Public Health Nutr 2016;19:3070-84. doi:10.1017/S136898001600104X

43 Nakamura R, Mirelman AJ, Cuadrado C, Silva-Illanes N, Dunstan I, Suhrcke M. Evaluating the 2014 sugar-sweetened beverage tax in Chile: An observational study in urban areas. PLoS Med 2018;15:e1002596. doi:10.1371/journal.pmed.1002596

44 Sassi F, Belloni A, Mirelman AJ, et al. Equity impacts of price policies to promote healthy behaviours. Lancet 2018:391:2059-70. doi:10.1016/S0140-6736(18)30531-2
45 Briggs AD, Mytton OT, Kehlbacher A, Tiffin R, Rayner M, Scarborough P. Overall and income specific effect on prevalence of overweight and obesity of $20 \%$ sugar sweetened drink tax in UK: econometric and comparative risk assessment modelling study. BMJ 2013;347:f6189. doi:10.1136/bmj.f6189

46 Flint E, Webb E, Cummins S. Change in commute mode and bodymass index: prospective, longitudinal evidence from UK Biobank. Lancet Public Health 2016;1:e46-55. doi:10.1016/S24682667(16)30006-8

47 Hanson S, Jones A. Is there evidence that walking groups have health benefits? A systematic review and meta-analysis. Br / Sports Med 2015;49:710-5. doi:10.1136/bjsports-2014-094157

48 Euromonitor International. Per capita market size of food groups. 2019. www.euromonitor.com/ [Accessed 13 July 2019].

49 Chow CC, Hall KD. Short and long-term energy intake patterns and their implications for human body weight regulation. Physiol Behav 2014;134:60-5.

50 Malik VS, Schulze MB, Hu FB. Intake of sugar-sweetened beverages and weight gain: a systematic review. Am J Clin Nutr 2006;84:27488. doi:10.1093/ajcn/84.2.274

51 Appelhans BM, French SA, Tangney CC, Powell LM, Wang Y. To what extent do food purchases reflect shoppers' diet quality and nutrient intake? Int I Behav Nutr Phys Act 2017;14:46.

52 Colchero MA, Zavala JA, Batis C, Shamah-Levy T, Rivera-Dommarco JA. Changes in prices of taxed sugar-sweetened beverages and nonessential energy dense food in rural and semi-rural areas in Mexico. Salud Publica Mex 2017;59:137-46.

53 Fletcher JM, Frisvold DE, Tefft N. Non-linear effects of soda taxes on consumption and weight outcomes. Health Econ 2015;24:566-82. doi:10.1002/hec.3045

Supplementary information: appendices 1-6 Supplementary information: technical appendix 